\title{
STRATEGI PENGEMBANGAN PARIWISATA BUMI SAKTI ALAM KERINCI KABUPATEN KERINCI, PROVINSI JAMBI
}

(Suatu Pendekatan Analitical Network Process)

Azita Yeja Casimeira a, 1, I Gst. Agung Oka Mahagangga a, 2

1 azita.yejacasimeira@ymail.com, ${ }^{2}$ ragalanka@gmail.com

a Program Studi S1 Destinasi Pariwisata,Fakultas Pariwisata,Universitas Udayana, Jl. Dr. R. Goris, Denpasar, Bali 80232 Indonesia

\section{ABSTRACT}

This research is about the management of which has been done and the development strategy of tourism "Bumi Sakti Alam Kerinci" province of Jambi Kerinci Regency. The purpose of this research is to know the application of management conducted by Disporaparbudbased on management functions and define the priorities of the development strategy will be undertaken. Data collection is done byobservation, interviews, libraryand documentation. Methods undertaken in this study analysed by Analitical chain processes are described qualitatively.

The results of this research are indicating not optimal tourism management made during this so do not provide optimal development impact. This research resulted in the development of 6 strategies well for the optimal development of tourism kerinci. The strategy is calculated in advance does it weigh against management functions, and then produce a development strategy a priority in future development.

Key Words: Development strategy, tourism management, Bumi Sakti Alam Kerinci.

\section{PENDAHULUAN}

Pariwisata merupakan suatu hal yang memiliki pengaruh penting dalam perkembangan suatu negara. Beberapa faktor pendorong Indonesia melakukan pengembangan pada sektor pariwisata adalah berkurangnya perananan minyak bumi sebagai sumber devisa negara, merosotnya nilai ekspor pada sektor nonmigas, adanya kecenderungan peningkatan pariwisata secara konsisten, besarnya potensi yang dimiliki oleh bangsa Indonesia bagi pengembangan pariwisata (Spilane, 1987).

Provinsi Jambi merupakan daerah yang dikenal kaya akan hutan dan dikembangkan sebagai pemasok kelapa sawit. Namun luput dari hal itu di Provinsi Jambi tepatnya

Kabupaten Kerinci memiliki beragam keindahan alam dan budaya menarik yang belum diketahui oleh khalayak. Kabupaten Kerinci memiliki slogan daerah yaitu "Bumi Sakti Alam Kerinci". Ini mengartikan daerah Kerinci merupakan daerah yang dikenal sakti, masih mempercayai kepercayaan nenek moyang tedahulu walaupun telah hidup serba modern. Hal ini dapat terlihat dalam kekentalan budaya masyarakat kerinci dalam menjalankan adat istiadat daerahnya. Walaupun kaya akan alam dan budaya yang menarik, Kabupaten Kerinci ini tidak terdengar sebagai daerah wisata potensial. Yang paling kentara adalah kemerosotan jumlah kunjungan wisatawan ke Kabupaten Kerinci setiap tahunnya mencapai 24 \% (Kerinci Dalam Angka, 2014). Semestinya dengan adanya pengembangan dan pengelolaan terarah, Kabupaten Kerinci dapat berkembang sebagai daerah pariwisata potensial di Sumatera. Untuk itu berdasarkan fenomena diatas penelitian tentang pengelolaan dan strategi pengembangan wisata, menjadi penting untuk dilakukan. Tujuannya adalah untuk mengoptimalkan pengembangan wisata Kabupaten Kerinci sehingga dapat dikunjungi oleh lebih banyak wisatawan.

\section{METODE PENELITIAN}

\subsection{Rancangan Penelitian}

Penelitian ini menerapkan metode penelitian kualitatif dan kuantitatif. Mendeskripsikan hasil penelitian yaitu berupa informasi yang relevan meliputi gambaran umum, permasalahan yang sedang dialami oleh pariwisata Kerinci, jumlah kunjungan wisatawan dan menghitung skala rancangan penentuan prioritas strategi dengan menggunakan Analitical Network Process (ANP).

\subsection{Teknik Pengumpulan Data}

Data tersebut didapatkan dari hasil observasi, wawancara, studi kepustakaan, dan dokumentasi. Penelitian ini menggunakan proses wawancara mendalam, teknik 
penentuan informan dalam penelitian adalah purposive sampling. Informan yang dipilih pertama adalah Kepala bidang pariwisata Diporaparbud Kabupaten Kerinci, staff pengembangan Taman Nasional kerinci Seblat (TNKS) dan masyarakat.

\subsection{Alur Penelitian}

Dalam tahap awal penelitian ini akan menganalisis data kualitatif terlebih dahulu. Miles dan Huberman (2007) menyatakan bahwa terdapat tiga macam kegiatan analisis data kualitatif, yaitu reduksi data, display data dan verifikasi kesimpulan. Kemudian dianalisis dengan suatu pendekatan Analitical Network Process (ANP). ANP adalah metode pengambilan keputusan yang mampu menangkap pengaruh (dependence) antar komponen secara timbal balik (feedback), mengkombinasikan dan mengkomparasi nilainilai intangible dan judgement subyektif dengan data-data rasio (Saaty, 2001). pengambilan keputusan untuk memilih alternatif, perancangan, prioritas, prediksi lebih akurat, dan hasil yang stabil. Dalam penelitian ini ANP digunakan untuk menentukan prioritas strategi yang akan dilakukan untuk pengembangan pariwisata Kabupaten Kerinci.

\section{PEMBAHASAN}

\subsection{Atraksi}

Kabupaten Kerinci merupakan suatu daerah di Provinsi Jambi yang berhawa sejuk dan memiliki segudang kekayaan alam yang dapat dikembangkan.sebagai daerah pariwisata potensial. Daerah ini dikenal dengan "3Ter" yaitu memiliki Gunung Kerinci sebagai "Atap Sumatera" (Top of Sumatera) atau dikatakan sebagai gunung vulkanik ter-tinggi di Indonesia, lalu Danau Gunung Tujuh merupakan danau ter-tinggi di Asia Tenggara, dan Perkebunan Teh Kayu Aro merupakan kebun teh ter-luas di Asia Tenggara. Kabupaten Kerinci merupakan daerah sakti, bersuku adat yang telah modern tetapi sampai saat ini tidak melupakan hal magis, tata adat dari nenek moyang dahulu. Hal inilah yang membuat Kerinci dinamai "Bumi Sakti Alam Kerinci". Selain itu Kabupaten Kerinci juga memiliki Danau Kerinci dan Taman Nasional Kerinci Seblat (TNKS) yang termasuk dalam wisata unggulan Kabupaten Kerinci.

\subsection{Pelaksanaan Pengelolaan Pariwisata Kabupaten Kerinci}

Untuk saat ini secara menyeluruh pariwisata di Kabupaten Kerinci dikelola oleh dua instansi yaitu Dinas Pemuda Olahraga Kebudayaan dan Pariwisata, serta Taman Nasional Kerinci Seblat (TNKS) dan dibantu oleh pihak masyarakat sekitar daya tarik wisata yang ada di Kabupaten Kerinci. Untuk mengetahui strategi pengembangan pariwisata Kerinci kedepannya maka harus mencermati sebelumnya pelaksanaan pengelolaan berdasarkan fungsifungsi manajemen kepada Daya Tarik Wisata unggulan Kabupaten Kerinci yaitu perencanaan, pengorganisasian, penggerakan dan pengawasan yang telah dijelaskan sebelumnya.

\section{3. $\quad$ Strategi Pengembangan}

Tahapan awal untuk merumuskan tahapan strategi berdasarkan penelitian yang telah dilakukan adalah dengan melihat masalah mendasar yang terjadi di Pengelolaan kepariwisataan Kabupaten Kerinci, sehingga akan menentukan kriteria solusi strategi yang diinginkan. Kemudian strategi pengembangan tersebut dikaitkan dengan manajemen pengelolaan dengan memberikan bobot nilai 15 pada fungsi-fungsi pengelolaan yaitu Planning, Organizing, Actuating, Controling (Terry, 2000). Bobot (1) menjelaskan bahwa keadaan manajemen pengelolaan terhadap strategi pengembangan tersebut Sangat Buruk. Bobot ini mengartikan bahwa strategi pengembangan terhadap keadaan manajemen tersebut tidak terpikirkan dan tidak memiliki dokumen.Bobot (2) menjelaskan bahwa keadaan manajemen pengelolaan terhadap strategi pengembangan tersebut Buruk yaitu mengartikan bahwa strategi pengembangan terhadap keadaan manajemen tersebut telah terpikirkan dan baru terprogram. Lalu bobot (3) menjelaskan bahwa keadaan manajemen pengelolaan terhadap strategi pengembangan tersebut Cukup, yang mengartikan bahwa strategi pengembangan terhadap keadaan manajemen tersebut telah terpikir dan terprogram tetapi belum jadi secara tuntas. Kemudian bobot (4) menjelaskan bahwa keadaan manajemen pengelolaan terhadap strategi pengembangan tersebut baik, yang mengartikan bahwa terprogram dengan baik tetapi belum teraplikasikan dengan baik. Bobot 
(5) menjelaskan bahwa keadaan manajemen pengelolaan terhadap strategi pengembangan tersebut sangat baik yaitu terprogram dengan baik dan telah teraplikasikan dengan baik.

Hasil dari pembobotan strategi pengembangan tersebut terhadap manajemen pengelolaan pariwisata Kabupaten Kerinci dijumlahkan permasing-masing fungsi manajemen pengelolaan dan nanti akan diklasifikasikan urutan prioritas dari strategi pengembangan yang akan dilakukan terhadap pariwisata Kabupaten Kerinci kedepannya.

Kendala Mendasar Dalam Pengelolaan Pariwisata Kabupaten Kerinci adalah Tidak adanya tenaga ahli khusus bidang pariwisata, tidak berjalan dengan baik aktivitas penerbangan bandara depati parbo, tidak terkonsep secara maksimalnya Festival Masyarakat Peduli Danau Kerinci (FMPDK), kurangnya promosi pariwisata Kabupaten Kerinci, tidak adanya travel agent khusus ke tempat-tempat wisata dan kurangnya sadar wisata masyarakat Kabupaten Kerinci. Berdasarkan beberapa kendala dalam pengelolaan pariwisata Kabupaten Kerinci yang telah dijelaskan diatas, maka strategi pengembangan yang akan dilakukan adalah sebagai berikut strategi perekrutan tenaga ahli khusus bidang pariwisata, strategi pembenahan Bandara Depati Parbo, strategi promosi yang lebih mendalam, strategi penyelenggaraan FMPDK yang lebih kreatif dan melibatkan kabupaten lain di Provinsi Jambi, strategi pengadaan Biro Jasa Perjalanana Wisata dan strategi pembinaan sumber daya manusia.

Setelah merumuskan beberapa strategi pengembangan yang dilakukan berdasarkan dari kendala-kendala yang ada, sesuai pendekatan Analitical Network Processs trategi tersebut, maka diberi pembobotan untuk mengetahui strategi yang menjadi prioritas utama dan alternatif. Keterangan pembobotannya dapat dilihat pada tabel 3.1 sebagai berikut:
Tabel 3.1

Rekapan Pembobotan Strategi Pengembangan Terhadap 4 Fungsi Manajemen Pariwisata Kabupaten Kerinci

\begin{tabular}{|c|c|c|c|c|c|c|}
\hline NO. & $\begin{array}{c}\text { STRATEGI } \\
\text { PENGEMBANGAN }\end{array}$ & $\mathrm{P}$ & 0 & A & C & Total \\
\hline 1. & $\begin{array}{l}\text { Strategi } \\
\text { Perekrutan } \\
\text { Tenaga Ahli } \\
\text { Khusus Bidang } \\
\text { Pariwisata }\end{array}$ & $2 / 16$ & $2 / 14$ & $1 / 10$ & $1 / 9$ & 0,478 \\
\hline 2. & $\begin{array}{l}\text { Strategi } \\
\text { pembenahan } \\
\text { Bandara } \\
\text { Depati Parbo }\end{array}$ & $4 / 16$ & $4 / 14$ & $3 / 10$ & $2 / 9$ & 1,057 \\
\hline 3. & $\begin{array}{l}\text { Strategi } \\
\text { Promosi yang } \\
\text { lebih } \\
\text { Mendalam }\end{array}$ & $4 / 16$ & $4 / 14$ & $3 / 10$ & $2 / 9$ & 1,057 \\
\hline 4. & $\begin{array}{l}\text { Strategi } \\
\text { Penyelenggara } \\
\text { an FMPDK } \\
\text { yang lebih } \\
\text { kreatif dan } \\
\text { melibatkan } \\
\text { Kabupaten } \\
\text { lain di } \\
\text { Provinsi Jambi }\end{array}$ & $2 / 16$ & $1 / 14$ & $1 / 10$ & $1 / 9$ & 0,407 \\
\hline 5. & $\begin{array}{l}\text { Strategi } \\
\text { pengadaan } \\
\text { Biro Jasa } \\
\text { Perjalanana } \\
\text { Wisata }\end{array}$ & $3 / 16$ & $2 / 14$ & $1 / 10$ & $1 / 9$ & 0,541 \\
\hline 6. & $\begin{array}{l}\text { Strategi } \\
\text { pembinaan } \\
\text { sumber daya } \\
\text { manusia }\end{array}$ & $1 / 16$ & $1 / 14$ & $1 / 10$ & $1 / 9$ & 0,345 \\
\hline
\end{tabular}

Sumber : Data diolah dari hasil penelitian 2015

Berdasarkan rekapan pembobotan strategi pengembangan terhadap 4 fungsi manajemen pariwisata kabupaten kerinci seperti pada tabel diatas menjelaskan bahwa total pembobotan pada strategi perekrutan tenaga ahli khusus bidang pariwisata adalah 0,478, kemudian strategi kedua strategi pembenahan bandara depati parbo mendapat total pembobotan 1,057. Strategi ketiga, strategi promosi yang lebih mendalam juga mendapatkan total pembobotan 1,057. Kemudian strategi keempat strategi penyelenggaraan FMPDK yang lebih kreatif dan melibatkan Kabupaten lain di Provinsi Jambi mendapat nilai 0,407 . Strategi kelima yaitu 
strategi pengadaan biro jasa perjalananan wisata mendapat total pembobotan 0,541.

Selanjutnya strategi yang terakhir adalah strategi pembinaan sumber daya manusia mendapatkan total pembobotan sebesar 0,345. Setelah merekap total dari pembobotan strategi-strategi tersebut maka terlihat Total tertinggi dan Total terendah. Total pembobotan tersebut lalu dapat diklasifikasikan tingkat prioritasnya menurut total pembobotan tersebut. Klasifikasi prioritas strategi dijelaskan pada tabel 3.2 berikut ini:

Tabel 3.2

Klasifikasi Prioritas Strategi

\begin{tabular}{|c|c|c|c|}
\hline NO. & $\begin{array}{c}\text { STRATEGI } \\
\text { PENGEMBANGAN }\end{array}$ & $\begin{array}{c}\text { TOTAL } \\
\text { PEMBOBOTAN }\end{array}$ & $\begin{array}{c}\text { TINGKAT } \\
\text { KLASIFIKASI }\end{array}$ \\
\hline 1. & $\begin{array}{l}\text { Strategi } \\
\text { Perekrutan } \\
\text { Tenaga Ahli } \\
\text { Khusus Bidang } \\
\text { Pariwisata }\end{array}$ & 0,478 & 4 \\
\hline 2. & $\begin{array}{l}\text { Strategi } \\
\text { pembenahan } \\
\text { Bandara Depati } \\
\text { Parbo }\end{array}$ & 1,057 & 1 \\
\hline 3. & $\begin{array}{l}\text { Strategi Promosi } \\
\text { yang lebih } \\
\text { Mendalam }\end{array}$ & 1,057 & 2 \\
\hline 4. & $\begin{array}{l}\text { Strategi } \\
\text { Penyelenggaraan } \\
\text { FMPDK yang } \\
\text { lebih kreatif dan } \\
\text { melibatkan } \\
\text { Kabupaten lain di } \\
\text { Provinsi Jambi }\end{array}$ & 0,407 & 5 \\
\hline 5. & $\begin{array}{l}\text { Strategi } \\
\text { pengadaan Biro } \\
\text { Jasa Perjalanana } \\
\text { Wisata }\end{array}$ & 0,541 & 3 \\
\hline 6. & $\begin{array}{l}\text { Strategi } \\
\text { pembinaan } \\
\text { sumber daya } \\
\text { manusia }\end{array}$ & 0,345 & 6 \\
\hline
\end{tabular}

Sumber : Data diolah dari hasil penelitian 2015

Berdasarkan Tabel diatas tentang klasifikasi prioritas strategi, menjelaskan tentang klasifikasi strategi menurut nilai pembobotan yang telah dilakukan sebelumnya. Nilai tertimggi akan menjadi prioritas utama untuk strategi pengembangan yang akan dilakukan, dan selanjutnya akan menajdi strategi alternatif. Strategi yang mendapatkan nilai pembobotan tertinggi (prioritas utama) adalah strategi pembenahan Bandara Depati Parbo yaitu dengan total pembobotan sebesar 1,057. Kemudian prioritas kedua yaitu strategi promosi yang lebih mendalam yang juga mendapatkan pembobotan yang sama yaitu 1,057. Selanjutnya di urutan ketiga dengan bobot 0,541 yaitu strategi yang akan dilakukan adalah strategi pengadaan biro jasa perjalanan wisata. Strategi perekrutan tenaga ahli khusus bidang pariwisata dengan total bobot 0,478 mendapat urutan keempat. Lalu diperingkat prioritas kelima dengan bobot 0,407 yaitu strategi penyelenggaraan FMPDK yang lebih kreatif dan melibatkan Kabupaten lain di Provinsi Jambi. Selanjutnya strategi terakhir yaitu strategi pembinaan sumber daya manusia diletakkan pada posisi prioritas paling terendah dengan total pembobotan 0,345 .

\section{Penutup}

\subsection{Simpulan}

Berdasarkan hasil penelitian dalam pelaksanaan pengelolaan dan penentuan skala strategi berdasarkan pengelolaan berdasarkan 4 fungsi manajemen, maka disimpulkan bahwa ada 6 strategi yang akan dilakukan untuk pengembangan wisata. Strategi tersebut di klasifikasikan untuk memilih prioritas yang akan dilakukan terlebih dahulu. Prioritas strategi tersebut adalah sebagai berikut:

1. Strategi Perekrutan Tenaga Ahli Khusus Bidang Pariwisata.

2. Strategi pembenahan Bandara Depati Parbo.

3. Strategi pembenahan Bandara Depati Parbo

4. Strategi Penyelenggaraan FMPDK yang lebih kreatif dan melibatkan Kabupaten lain di Provinsi Jambi.

5. Strategi pengadaan Biro Jasa Perjalanana Wisata.

6. Strategi pembinaan sumber daya manusia

\subsection{Saran}

Berdasrakan penelitian yang telah dilakukan tersebut makan dapat disarankan beberapa hal sebai berikut: 
1. Pemerintah yaitu Dinas Pemuda Olahraga Pariwisata dan Kebudayaan khususnya bidang pariwisata harus menerapkan dengan baik fungsi manajemen dalam pengelolaan agar dapat mengoptimalkan pengembangan terhadap pariwisata Kabupaten Kerinci.

2. Bekerja sama dengan masyarakat dan pihak TNKS dalam menerapkan strategi pengembangan dengan baik sesuai dengan prioritas strategi yang dilakukan, agar pengembangan dapat berjalanan sesuai tahap yang benar dan menghasilkan manfaat yang baik bagi perkembangan pariwisata Kabupaten Kerinci.

\section{DAFTAR PUSTAKA}

Disporaparbud Kabupaten Kerinci. 2015. Kerinci Dalam Angka 2014. Kabupaten Kerinci

Miles, Mattew B dan A. Michael Huberman.2007. Analisis Data Kualitatif.Jakarta : Universitas Indonesia Press

Saaty, T.L. 2001. Decision making with dependence and feedback: The Analytical Network Process. Pittsburgh

Spillane J.J. 1987. Pariwisata Indonesia Sejarah dan Prospeknya. Yogyakarta, Kanisius. 150 halaman

Terry, George R. Prinsip-Prinsip Manajemen. Jakarta: PT. Bumi Aksara. 2000 